\title{
Evaluating investments in flexible on-demand production capacity: a real options approach
}

\author{
Bettina Freitag $^{1} \cdot$ Lukas Häfner $^{1,2}$ (D) \\ Verena Pfeuffer ${ }^{1} \cdot$ Jochen Übelhör $^{1,2}$ (D)
}

Received: 30 December 2017/ Accepted: 21 November 2019/Published online: 2 December 2019

(C) The Author(s) 2019

\begin{abstract}
Ongoing digitalization of production accelerates trends like mass customization, ever shorter lead times, and shrinking product life cycles. Thereby, industrial companies face increasingly volatile demand that complicates an appropriate production capacity planning. On the other hand, the comprehensive digitalization of production environments favors, amongst others, the dynamic integration of flexible external on-demand production capacity provided by specialized external capacity providers (ECPs). To enable the usage of on-demand production capacity, industrial companies may require significant upfront investments (e.g., for inter-organizational information systems, planning and organizational processes, employee training). The objective of this paper is to develop a model that evaluates such enabling upfront investments from the perspective of a manufacturing company. To consider flexibility of action, we apply real options analysis in a discrete-time binomial tree model and weigh these so-called expansion options to related cash outflows. In addition, we evaluate our model by means of a simulation and sensitivity analyses and derive insights for both researchers and practitioners. The insights gained by our model present a profound economic basis for investment decisions on upfront investments in flexible on-demand production capacity.
\end{abstract}

Keywords Investment evaluation · On-demand production capacity · Volume flexibility $\cdot$ Real options analysis $\cdot$ Expanded net present value $\cdot$ Digitalization

Jochen Übelhör

jochen.uebelhoer@fim-rc.de

1 FIM Research Center, University of Augsburg, Universitätsstraße 12, 86159 Augsburg, Germany

2 Project Group Business and Information Systems Engineering of the Fraunhofer FIT, Augsburg, Germany 


\section{Introduction}

With the rise of online market places like Amazon and Alibaba, and the on-demand availability of almost any product imaginable, manufacturing companies in all industries face significant challenges in their capacity planning. Customers now expect highly individualized products, instant availability, and ever-shorter time-tomarket and delivery times (Garrido 2012). This is also the case in the business-tobusiness sector, in which individualized, engineered-to-order business models are increasingly important (Mosig et al. 2017). The effects of these developments are intensified by globalization and technological progress, which lead to reduced product life-cycles in, for instance, the electronics, semiconductor, toy, and fashion industries (Alaniazar 2013). In particular, demand for highly individualized products which cannot, economically, be produced for stock (and are thus comparable to services, which cannot be physically stored) encourages companies to switch from traditional make-to-stock to flexible make-to-order (MTO) manufacturing approaches. Yet, when it comes to MTO capacity management, volatile customer demand complicates investment decisions in new production facilities. Depending on the particular technology, the amortization period of such investment may span several years. What is more, miscalculations during investment planning may result in idle capacity or capacity shortages, both of which are likely to have negative economic consequences. While idle capacity incurs idle costs, capacity shortages result in longer delivery periods and, in the case of dissatisfied customers, loss of customer lifetime value. Hence, MTO approaches which do manage to meet volatile customer demand are usually those that benefit from more flexible capacity management, which allows companies to adjust their production in the short term. This type of flexibility is known as volume flexibility (Wickramasinghe and Perera 2016).

Instead of investing in new production facilities, companies obtain volume flexibility by commissioning external capacity providers (ECPs) who offer manufacturing-as-a-service (MaaS) (Rauschecker et al. 2014). More precisely, ECPs offer flexible production on-demand using their own production facilities or those of a network. Thereby, they deliver and install on-demand production capacity to the customer's factory or, if geographical distance makes it logistically feasible, may offer remote production. In return, the ECP can charge pay-per-use fees, as is common practice among businesses offering on-demand production capacity (Xu 2012). ECP services can be particularly profitable for small- and medium-size enterprises (SMEs), which usually have lower investment budgets. The overarching digitalization of the industrial sector enables companies to commission ECPs, and utilize on-demand production capacity, thanks to lower machine setup costs resulting from easier (IT-based) integration (so called plug-and-produce) and multifunctionality of leasable production facilities. Moreover, digitized production infrastructures significantly simplify MTO approaches, thanks to the fact that related Cyber-Physical Production Systems (CPPSs), which "synergize conventional production technology and IT" (Penas et al. 2017: p. 55), support the mass customization of products in ever smaller batch sizes down to lot-size one (Gerhard 
2017). Compared to production costs in traditional environments, costs in CPPSs are comparatively low (Brettel et al. 2014; Wang et al. 2016), which makes outsourcing to low wage countries less attractive (Katzmarzik et al. 2012). The return of manufacturing from globally distributed to local (near-customer) factories can also help to fulfil time-sensitive customer demand. However, factories focusing on local markets are subject to more volatile customer demand, i.e., machine utilization is less predictable than in factories which manufacture for customers worldwide. Hence, digitized production favors ECP business models, and MTO approaches and companies which offer local production benefit from volume flexibility as offered by ECPs (Matt et al. 2015).

The emerging trend of ECP services is widely evident. For instance, the US online shop eMachineShop of the Micro Logic Corporation offers "easy, convenient and low-cost fabrication of custom parts", which are ordered "via the web" and produced in the company's own facilities (eMachineShop 2017). Relying on a business network, Xometry Inc. offers "custom parts through hundreds of manufacturers across the United States" (Xometry 2017). Both of these ECPs offer remote production using $3 \mathrm{D}$ printing, and have in common that customers firstly upload or create a CAD model via the respective website, secondly, receive feedback on prices, lead times, and production processes, and, thirdly, submit the order. Another example is EMAG Group, a German supplier of manufacturing systems which covers "the whole process chain, from soft to hard machining" and builds production facilities for "turning, drilling, milling, gear cutting, grinding, laser welding [...]" (EMAG 2017). EMAG offers its production facilities for lease to "assist companies in reacting to peaks or losses in production, or to bridge the waiting period for delivery of a new machine or the time taken to recondition/modify an existing one" (EMAG 2017). Although these companies already provide ondemand production capacity, the business models of ECPs may be further extended in the future. For example, ECPs may offer cloud manufacturing, i.e., "a customercentric manufacturing model that exploits on-demand access to a shared collection of diversified and distributed manufacturing resources to form temporary, reconfigurable production lines which enhance efficiency, reduce product lifecycle costs, and allow for optimal resource loading in response to variable-demand customer generated tasking" (Wu et al. 2013: p. 1). Cloud manufacturing strives to provide "centralized operation management of the services, choice of different operation modes and embedded access of manufacturing equipment and resources" (Xu 2012: p. 79). Those ECPs which offer cloud manufacturing may publish their services in a cloud platform that matches customer inquiries with a producer based on their qualitative and quantitative parameters, establishes and executes a (virtual) manufacturing system, and enables ECP performance evaluation, fee calculation, and payment processing (Ren et al. 2017).

Independent of the established ECP business model, the rise of MaaS has the potential to provide industrial companies with additional volume flexibility, accessed on-demand and without permanent capacity expansion, to successfully enable MTO approaches. However, on-demand production capacity comes at a price. On the one hand, the use of on-demand production capacity fosters companies' dependence on ECPs. It also requires the sharing of highly sensitive 
information, which could ultimately lead to hold-up problems (Haruvy et al. 2018). On the other hand, access to on-demand production capacity (and, therefore, volume flexibility) is likely to require initial upfront investments, e.g., for additional interface technologies such as inter-organizational information systems, the standardizing of planning and organizational processes, employee training, and fees such as availability guarantees for production facilities. Given the costs associated with these investments, the profitability of on-demand production capacity is highly dependent on the industrial companies' customers, in particular their changing preferences and, thus, the development of customer demand over time. This is to say that highly uncertain and volatile customer demand favors corresponding upfront investments, as companies then possess volume flexibility which allows them to expand their otherwise rigid internal production capacity as needed.

Investments in on-demand production capacity have to be evaluated in terms of the resultant managerial flexibility in response to the uncertain development of demand. Yet, this is a complex task, and companies which follow principles of value-based management require appropriate methods for decision-support which do not yet exist (cf. Section 2). Hence, the aim of this paper is to develop a valuation method that addresses this situation. Thereby, real options analysis (ROA) comes into consideration which is "an adjusted version of decision tree analysis, involving a redistribution of probability masses such that risk is reallocated in a way that allows for discounting by the risk-free rate" (Benaroch and Kauffman 2000: p. 202). ROA is an established method for evaluating investments which focuses on the flexibility of managerial action in response to uncertainty. Accordingly, in this paper, we address the following research question:

RQ How can an industrial company evaluate investments in on-demand production capacity considering managerial flexibility of action due to volume flexibility and uncertainty in demand?

To answer this research question, we model and evaluate volume flexibility as a set of expansion options, and integrate the respective option values in an economic analysis of upfront investments using an expanded net present value approach (ENPV). Our research addresses a relevant real-world problem as an answer could facilitate investment decision-making in the course of industrial companies' production capacity planning. The remainder of this paper is structured as follows: In Sect. 2, we review related work on manufacturing strategies, capacity planning, investment evaluation methods, and-in particular-ROA. In Sect. 3, we describe our research scenario, introduce basic assumptions, and present our model, which evaluates expansion options for on-demand production capacity. Afterwards, in Sect. 4, we demonstrate our model using an exemplary base case and then evaluate the validity and robustness of the model using randomly chosen simulations and subsequent sensitivity analyses. In Sect. 5, we discuss the managerial implications. Finally, in Sect. 6, we conclude our paper by addressing limitations and presenting an outlook for future research. 


\section{Theoretical background, related work, and research method}

In the following, we present related work to our research. Firstly, we discuss manufacturing strategies and capacity planning in the industrial sector. Secondly, we elaborate on investment evaluation methods in general before focusing our discussion on ROA.

\subsection{Manufacturing strategies and capacity planning}

Companies may follow various different manufacturing strategies. Olhager and Östlund (1990) describe a "manufacturing continuum ranging from make-to-stock over assemble-to-order and make-to-order to engineer-to-order [...]" (p. 136). They discuss the customer order point (COP), i.e., the point in a manufacturing process at which a product is matched with an individual customer order. Depending on the degree of customization, the COP may vary between finished products in a make-tostock concept and raw materials in an MTO concept (Olhager and Östlund 1990). Customized production and mass customization favor flexible MTO approaches. Chen et al. (2003) highlight the fact that MTO approaches require the close integration of suppliers, manufacturers, assemblers of components, and distributors of finished products to ensure short lead times. Thereby, digitalization favors the "integration of several different companies through value networks" (Kagermann et al. 2013: p. 6). As a result, new forms of collaboration become feasible. For example, embedded manufacturing systems are vertically connected to business processes and horizontally networked with other business partners (Wang et al. 2016). Brettel et al. (2014) argue that "boundaries of companies deteriorate" (p. 37) and that collaborative manufacturing becomes increasingly important. As a result of this trend in networked manufacturing, new business models (such as ECPs) emerge and open new market opportunities for companies (Kagermann et al. 2013; Monostori 2014).

As MTO approaches are especially prone to mistakes in capacity planning (cf. Section 1), such manufacturing strategies benefit from the opportunity to flexibly outsource production. Respective make-or-buy decisions in capacity planning have been well researched in the literature (Chase et al. 2004). Kremic et al. (2006) conduct an extensive literature review and conclude that motivations for outsourcing fall into three main categories: cost, strategy, and politics (the latter mostly in the case public organizations). Transaction-cost theory is often used to investigate the cost-saving potential of specialization and economies of scale, while the resource-based view is widely used to explain outsourcing from a strategic perspective (Boulaksil and Fransoo 2010). In the latter case, companies apply outsourcing to concentrate on core competencies, or to have more flexibility to manage uncertain demand (Lankford and Parsa 1999). Decision support for capacity planning and the outsourcing of physical production is also well researched. For instance, Tomlin (2006) investigates the effects of volume flexibility on sourcing and contingent routing strategy in a single-product setting in the event that a company has the choice between different types of suppliers with and without 
volume flexibility. Applying Tomlin's approach, companies can investigate different capacity and sourcing strategies-particularly in the case of disruptions - to evaluate the volume flexibility of their suppliers. Dong and Durbin (2005) investigate surplus markets, on which suppliers can flexibly sell excess component inventory to other manufacturers experiencing a shortage. They illustrate that suppliers can profit from the opportunity to sell excess inventory in the event of low transaction costs on the surplus market. Tsai and Lai (2007) develop a mathematical approach to optimal decision making in joint production settings. Using this approach, companies producing joint products can arrive at the most mutually advantageous decisions regarding capacity expansions and outsourcing.

In addition to the literature on dependent, company-internal, and incremental capacity choices, there is also literature on capacity choices that focuses on companies which choose not to periodically adjust their capacity but instead decide to source external capacity from ECPs. This allows the analysis of decision-specific components such as upper internal capacity limits and minimum contract sizes of ECPs. In terms of ECPs which provide services (rather than physical production), Akşin et al. (2008) research a call center and the problems it faces when making decisions about outsourcing, considering several frame conditions. The authors determine optimal capacity levels and characterize optimal pricing conditions for volume-based and capacity-based contracts offered by a vendor (ECP). Another example is the work of Dorsch and Häckel (2012), in which the authors investigate the on-demand exchange of excess capacity for cloud-services, and the effect that this has on excess capacity markets. They develop a mathematical model of the capacity-related optimization problem experienced by service providers with and without excess capacity, and find that flexibility offers economic benefits thanks to excess capacity markets. Furthermore, the same authors develop an optimization approach to investigate the effects that sourcing decisions have on operating costs for business processes, taking particular account of volatile demand and on-demand capacity from an external market (Dorsch and Häckel 2014). However, authors in the aforementioned research streams on capacity optimization focus on the optimal allocation of existing resources rather than on the provision of decision support for those deciding for or against flexibility-enabling investments.

\subsection{Investment evaluation methods}

A well-established method for evaluating investments is to calculate the Net Present Value (NPV), which is calculated by subtracting the present value of cash outflows from the present value of cash inflows. If a project's NPV is greater than zero, the project is worth the investment (Myers 1984). To account for project uncertainty (i.e., risks), cashflows can be additionally discounted using a risk-adjusted discount rate. An alternative approach is to adjust cashflows to risk, and discount the adjusted cashflows by the risk-free interest rate (Schwartz and Trigeorgis 2004). However, literature often claims that the NPV underestimates the value of a project as it does not capture managerial flexibility of actions (Kogut and Kulatilaka 1994; Schwartz and Trigeorgis 2004; Lee and Lee 2015), which is a major success factor for appropriate decision-making, particularly in the case of digitization projects (Brettel 
et al. 2014; Vyatkin et al. 2007; Lasi et al. 2014; Spath et al. 2013). As a result, strategically important projects are probably not undertaken as a result of incomplete valuations (Amram and Kulatilaka 1998).

One appropriate approach for capturing managerial flexibility of actions in response to uncertainty is ROA, which transfers option pricing models for financial assets to real-world investment decisions (Copeland and Antikarov 2003; Trigeorgis 1996). Both financial and real options include the opportunity, but not the obligation, to undertake a predetermined action at a future point in time (Luehrman 1998). Myers (1977) defines real options as "opportunities to purchase real assets on possible favorable terms" (p. 163). Depending on the kind of managerial flexibility, several types of real options exist, e.g., options to expand, to contract, to abandon, to defer, and to switch (Trigeorgis 1996).

In this paper, we apply ROA to evaluate a manufacturing company's flexibility to commission an ECP, which the company may use to address uncertain levels of customer demand. We model respective volume flexibility as an expansion option, which was traditionally defined as an option to "expand the project's scale by making an additional investment" (Trigeorgis 1993: p. 3). Dangl (1999) applies ROA to determine the optimal scale and timing of a manufacturing company's capacity expansion. The author concludes that uncertainty in the development of demand considerably increases the optimal scale of capacity expansion and deferral of investment. Similarly, Benavides et al. (1999) research the optimal scale and timing of capacity expansions within semiconductor industries. They focus on alternative capacity expansion designs, and conclude that uncertainty in demand development favors designs for sequentially deployable expansions and late investment decisions. Lier et al. (2012) research sequential expansion options for modular chemical plants which can be gradually expanded during a fixed project term. This modular approach increases the project value response to uncertain demand development, as compared to large-scale chemical plants which are, at the outset, built to their final stage of expansion. Fernandes et al. (2012) evaluate an option designed to enable a company to stop outsourcing and expand its own production capacity. They find that demand uncertainty considerably affects decisions about integration, i.e., about the occurrence and timing of internal capacity expansions.

In our case, however, additional production capacity is only available at times when the company is able to expansion option. Hence, our type of expansion option is similar to the option of altering the scale, which requires the kind of managerial flexibility that enables a company to "increase the scale of a project/system (and thus the range of potential benefits) if circumstances are favorable; or [...] reduce the scale (and thus potential losses) if circumstances are unfavorable" (Fichman et al. 2005: p. 25). Abel et al. (1996) implicitly model an option to change scale by evaluating a company's flexibility to both invest and disinvest in production capacity. They conclude that the option to disinvest incentivized the company to make previous investments. In the context of multistage enterprise resource planning (ERP) investment projects, Wu et al. (2009) evaluate several types of real options, including a company's option to change the scale at each stage of a project. 
As opposed to previous studies, in our case, option exercise initializes an external service and not an investment in the expansion of internal production capacity. In this vein, Benaroch et al. (2010) build a model for evaluating flexibility to out- and back-source IT service contracts. Contrary to our approach, they focus on an ECP's perspective, with the objective of identifying optimal contract flexibility in terms of service level agreements. In doing so, they neglect some aspects that we explicitly consider, such as the client company's potential for partial outsourcing (they apply an all-or-nothing approach), the possibility of increased costs if the client company's customers become dissatisfied, and an evaluation of necessary upfront investments. Wu et al. (2001) and Wu et al. (2002) research long-term contracting agreements and spot markets for non-storable goods and services. They differentiate between several cases involving single and multiple buyers and sellers, applying von Stackelberg game-based theoretical frameworks to determine the prices at which market equilibrium is achieved. Thereby, Wu et al. (2001) evaluate long-term capacity options (which buyers obtain from sellers) based on Black and Scholes' (1973) and Merton's (1973) evaluations of options. This approach was further developed by Spinler et al. (2002) to include not only spot price uncertainty but also demand and cost uncertainty, and, subsequently, by Spinler et al. (2003) with a view to evaluating risk-sharing between the trading partners. Like our approach, all of these option pricing models based on Wu et al. (2001) consider a seller's reservation price (in our case: minimum contract size) and, if capacity is called, execution fee per unit of output. However, for our purposes, these models do not suit, as our aim is to model a company's (temporal) outsourcing decision problem, which yields additional dependencies on internal production costs, internal production capacity, and customer satisfaction. Klaus et al. (2014) built a model for IT-service providers to outsource excess demand to an ECP if internal service capacity is insufficient. Like us, they weigh the value of their option against the necessary upfront investments, while option exercise triggers costs for external service activation. Further similarities are their consideration of partial outsourcing and dissatisfied customers. However, these authors limit their approach to a one-time outsourcing decision, which must fully compensate the company for upfront investments. In contrast, we allow for several sequential outsourcing decisions: i.e., for a company's initial decision-making on upfront investments, we evaluate multiple (temporal) expansion options. Furthermore, we extend Klaus et al.'s (2014) approach by allowing the ECP to demand a minimum contract size. Despite their differences, the studies by Benaroch et al. (2010), Wu et al. (2001), and Klaus et al. (2014) have an essential property in common with our objective: Due to the trend toward highly individualized products, we consider a company that applies an MTO approach with no production of stock, which is similar to those authors' application context of ITservices that cannot be physically stored. In the context of manufacturing, we found only one other paper that uses ROA to evaluate temporal capacity expansion of companies with MTO approaches: Kleinert and Stich (2010) address companies in the machinery and equipment industry that source subcomponents from suppliers. As unforeseen problems might occur during the manufacturing process, these authors recommend that such companies consider the purchase of additional expansion options from their suppliers. Like our approach, a client company, 
therefore, weighs costs for enabling (purchasing) the expansion option-and for the actual option exercise against adverse effects of time delays (customer dissatisfaction in our case). However, their approach is rather conceptual and is not transformed into a valuation formula. Unlike our approach, their expansion option only refers to a single customer order, and the possibility that the company might produce subcomponents internally is excluded.

To the best of our knowledge, existing literature is insufficient for our purposes, which has encouraged us to develop an appropriate approach for the evaluation of investments which enable the commissioning of ECPs, i.e., recourse to flexible, ondemand production capacity. Thereby, neither an isolated NPV approach nor an isolated ROA is sufficient: instead, a combination of both approaches seems promising. Panayi and Trigeorgis (1998) introduce the ENPV approach, which enhances the common NPV by integrating ROA. ${ }^{1}$ For example, investments in a software platform can be evaluated using the ENPV approach: such a project is likely to exhibit a negative NPV for the platform itself, but may become profitable when the flexibility to develop additional software applications on this platform is taken into account. In this paper, we also apply an ENPV approach. Since our scenario considers the evaluation of upfront investments without considering further deterministic cashflows, it is kept deliberately simple (i.e., the NPV equals cash outflows due to upfront investments). More precisely, in our scenario, the business case of upfront investments must solely pay off by obtained flexibility of action. Nevertheless, our approach can be easily extended for scenarios with additional cash inflows and outflows of the initial (enabling) project. We introduce our ENPV approach in the following section.

\section{Evaluation of on-demand production capacity}

In this section, we present our ENPV approach, including ROA. Therefore, we firstly describe our scenario of an MTO production setting. Secondly, we elaborate on assumptions inherent in the model before presenting our approach for modeling and evaluating volume flexibility using on-demand production capacity as an expansion option.

\subsection{Scenario}

As previously mentioned, we consider an industrial company that manufactures highly individualized products using an MTO approach. Customers expect the company to deliver products within a contractually stipulated timeframe. The rate of incoming customer orders is highly volatile and, thus, the company must have an appropriate capacity planning. The central tradeoff for the company is between idle capacity and capacity shortages. Seeking volume flexibility, the company considers commissioning an ECP that offers flexible production capacity on-demand. We

\footnotetext{
${ }^{1}$ Expanded Net Present Value $($ ENPV) $=$ Traditional NPV + Value of real options (similar to Panayi and Trigeorgis 1998).
} 
assume that the ECP's business model is based on a contractually specified pay-peruse payment model, i.e., the industrial company pays for each unit produced externally. The contract also specifies a minimum contract size for activating the external service, which the company must meet to ensure a minimum return for the ECP. Commissioning on-demand production capacity also requires initial upfront investments in, for example, additional interface technologies such as interorganizational information systems, the standardization of planning and organizational processes, employee training, and fees such as availability guarantees for the ECP's production facilities. In sum, the company faces the challenge to (ex ante) evaluate the business value of volume flexibility using on-demand production capacity, taking into account both the necessary upfront investments and the highly volatile nature of customer orders. In the following we present our model, which addresses this real-world problem using ROA. Firstly, however, we introduce the necessary assumptions.

\subsection{Basic scenario and model assumptions}

We consider a time horizon with regard to an arbitrary time $t_{n}$ for the company's capacity planning. $t_{0}$ is the current point in time, at which the company must decide whether to sign a framework contract with an ECP for a contract term extending until $t_{n}$. This contract specifies the company's right to use on-demand production capacity (i.e., to activate the ECP's service) at $n \in \mathbb{N}$ equally distributed times $t_{i}$ with $i \in[1, n]$ which divide the planning horizon until $t_{n}$ into $n$ equal periods. More precisely, this means that, if the company signs the framework contract in $t_{0}$, it can decide $n$ times whether seizing on-demand production capacity is (for the duration of one period) preferable given the current volatility of customer demand (Fig. 1). In terms of ROA, the company can sign the framework contract to purchase $n$ independent expansion options from the ECP. We enumerate expansion options with $i \in[1, n]$ and refer to the maturity date of each option using $T_{i}=t_{i}$.

The objective of our approach is to investigate whether or not the company should sign the framework contract with the ECP. This involves comparing the value of the expansion options available to the company with the cash outflows required for the necessary upfront investments. As stated above, we apply an ENPV approach to evaluate the company's overall business case $\left(V_{0}\right)$ :

$$
V_{0}=\sum_{i=1}^{n} C_{T_{i}}\left(t_{0}\right)-I\left(t_{0}\right)
$$

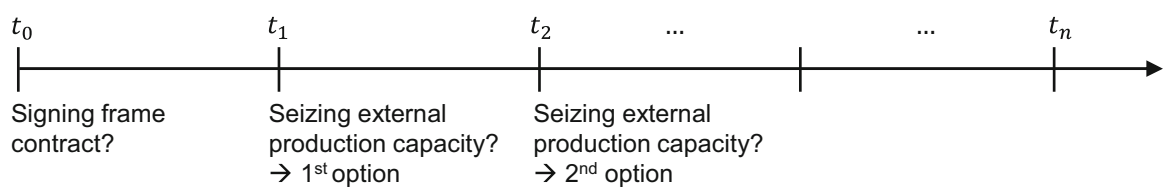

Fig. 1 Planning horizon in the Basic Scenario 
Thereby, $C_{T_{i}}\left(t_{0}\right)$ is the present value of the expansion option with a maturity date in $T_{i}$ from the perspective of $t_{0}$. Accordingly, $I\left(t_{0}\right)$ is the sum of cash outflow for necessary upfront investments in $t_{0}$, which is independent of expansion options' exercise. More precisely, as the company decides for or against upfront investments at the current point in time $t_{0}$, these upfront investments do not influence the company's future decision making on exercising (temporal) expansion options. If the business case yields $V_{0}>0$, signing the framework contract with the ECP is preferable.

The company sells its MTO products to generate revenue. We assume highly volatile customer demand which yields (for a specific MTO product) a total periodical revenue $R\left(t_{i}\right)$. We choose $R\left(t_{i}\right) \geq 0$ to be our only stochastic variable for determining the value of the expansion option since this is a monetary quantity which facilitates the application of ROA (compared to, for instance, the modeling of volatile customer orders).

Assumption $1 \quad R\left(t_{i}\right)$ follows a multiplicative (stochastic) binomial process over discrete time periods with a constant mean $\mu>0$ and standard deviation (volatility) $\sigma>0$. The company observes $R\left(t_{0}\right)$ at the current point in time $t_{0}$ and uses this information to predict uncertain future revenues $R\left(t_{i}\right)$.

Moreover, the company possesses a fixed internal production capacity which can process a certain (periodical) maximum revenue $\bar{R} \geq 0$. We assume revenue per unit sold and respective internal production costs $k_{\text {int }} \in[0,1]$ (as a proportion of this revenue) to be constant for all customers and all periods until $t_{n}$. Thus, for $R\left(t_{i}\right) \leq \bar{R}$, $k_{\text {int }} * R\left(t_{i}\right)$ refers to the company's total internal production costs in $t_{i}$.

Assumption 2 The company's maximum revenue $\bar{R}$, revenue per unit sold, and internal production costs $k_{\text {int }}$ are constant until $t_{n}$. Thereby, $\bar{R}$ is a multiple of revenue per unit sold.

Because of the current trend toward MTO approaches, we do not consider stocks of finished products. Due to customer expectations of ever-shorter lead times, we assume that customers will become dissatisfied if the company does not process their orders within a certain time frame.

Assumption 3 Customers expect the company to process their order within a certain time frame which equals one planning period (e.g., 1 month). If the company cannot deliver a product within this time frame, the respective production costs rise to $k_{\text {dis }}$, with $k_{\text {dis }}>k_{\text {int }}$ representing the cost of dissatisfied customers.

Thus, if $R\left(t_{i}\right)$ exceeds $\bar{R}$ at time $t_{i}$, the production costs associated with dissatisfied customers $k_{\text {dis }}$ are incurred and apply to all excess revenue $R\left(t_{i}\right)-\bar{R} \geq 0$. In practice, $k_{\mathrm{dis}}$ may result from contractual penalties incurred due to the violation of service level agreements, loss of customer lifetime value, loss of reputation, loss of revenue due to the rejection or cancellation of orders, or a combination of these factors.

However, if an ECP is available, the company can use on-demand production capacity to avoid customer dissatisfaction. At expansion option $i$ 's maturity date $T_{i}$, 
the company reviews its current periodical revenue $R\left(T_{i}\right)$ (which is then known) to determine if production costs could be lowered using the ECP's production capacity. To reduce complexity, we neglect the fact that the ECP's production capacity is limited and may involve supply-dependent pricing structures.

Assumption 4 The ECP's production capacity is high enough to meet the company's excess revenue, and the ECP charges constant unit prices (i.e., external production costs, from the client company's perspective) of $k_{\text {ext }}$ with $k_{\text {dis }}>k_{\text {ext }}>k_{\text {int }}$. Like $k_{\text {int }}$ and $k_{\text {dis }}$, $k_{\text {ext }}$ is proportional to the company's revenue per unit sold.

As the ECP aims to generate profit, it is reasonable to assume that corresponding external production costs per unit $k_{\text {ext }}$ are higher than internal production costs per unit $k_{\text {int }}$. In addition, $k_{\text {ext }}$ must be lower than $k_{\text {dis }}$; otherwise, the ECP will not be competitive. As described in Sect. 3.1, the company's contract with the ECP specifies a minimum contract size MCS every time $t_{i}$ the company exercises an expansion option, i.e., draws on the on-demand production capacity. As $k_{\text {ext }}$ is constant, $\underline{R}$ refers to the minimum revenue the company must draw from its customers to yield the required MCS with the ECP, i.e., $\underline{R}=\frac{\mathrm{MCS}}{k_{\mathrm{ext}}}$.

Assumption 5 MCS and $\underline{R}$ are constant until $t_{n}$. If the company does not meet the agreed MCS, it must pay the difference.

Both $\underline{R}$ and MCS significantly influence the activation of external services. Finally, to modify and apply the binomial tree model of Cox et al. (1979) (Sect. 3.3.2), we require a rather technical assumption.

Assumption 6 The company is a risk-neutral decision maker.

\subsection{Modeling an expansion option for on-demand production capacity}

In this section, we present our ROA. Firstly, we describe the decision the company must make about seizing on-demand production capacity. Secondly, we develop our option evaluation model based on Cox et al. (1979).

\subsubsection{Decision problem of seizing on-demand production capacity}

The decision problem focuses on total periodical revenue $R\left(t_{i}\right)$, as $R\left(t_{i}\right)$ is the only stochastic parameter in our model. Starting at $t_{i}=t_{0}$, we model $R\left(t_{i}\right)$ as a multiplicative binomial process, i.e., as a binomial tree that forks at each discrete point in time $t_{i}$ into two different values, both of which reflect uncertainty. One value represents a possible future increase in $R\left(t_{i}\right)$; the other, a possible future decrease. We illustrate an exemplary binomial tree with a time horizon of three periods in Fig. 2.

We introduce $u>1$ and $d<1$ as factors for upward and downward movement of $R\left(t_{i}\right)$, respectively. Thereby, starting at $t_{0}, R_{u_{t_{0}}}\left(t_{1}\right)=R\left(t_{0}\right) * u$ represents a possible (future) increase in the total periodical revenue, whereas $R_{d_{t_{0}}}\left(t_{1}\right)=R\left(t_{0}\right) * d$ 


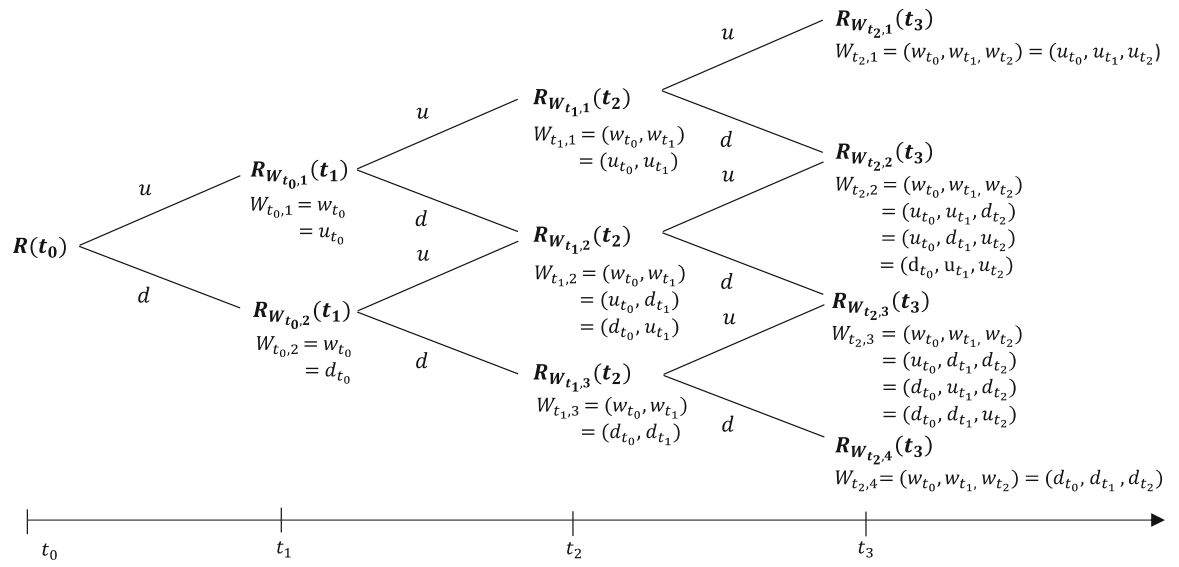

Fig. 2 Binomial tree of the total periodical revenue $\boldsymbol{R}\left(\boldsymbol{t}_{\boldsymbol{i}}\right)$

represents a possible (future) decrease. At time $t_{i}$, the binomial tree possesses $i+1$ different nodes. $W_{t_{i-1}, s}=\left(w_{t_{0}}, w_{t_{1}}, \ldots, w_{t_{i-1}}\right)$ indicates the filtration or "history" of upward and downward movements previous to $t_{i}$, with $w_{j} \in\left\{u_{j}, d_{j}\right\}, \mathrm{j} \in\left\{t_{0}, t_{1}, \ldots\right.$, $\left.t_{i-1}\right\}$, and $s \in\{1, \ldots, \mathrm{i}+1\}$ used to number different nodes at time $t_{i}$. This filtration helps to unambiguously identify different nodes at a certain point in time $t_{i}$, which is necessary for implementing our algorithm. However, for the sake of readability, we explain the following with a reduced notation that waives all filtrations.

At time $t_{i}=T_{i}$, the company must decide to exercise an expansion option. Therefore, it observes the total revenue of the current period $R\left(T_{i}\right)$ and computes the total production costs with $\left(\mathrm{TPC}_{\mathrm{Ex}}\right)$ and without $\left(\mathrm{TPC}_{\mathrm{NoEx}}\right)$ recourse to on-demand production capacity. The former represents an exercise of the expansion option, the latter represents no exercise. Afterwards, the company subtracts the respective total production costs from the total revenue of the current period (which the company observes) analogous to common option pricing theory. Note that, due to our modelling of cost structure $\left(k_{\mathrm{dis}}\right.$ also includes lost revenue resulting from insufficient production capacity), in both cases (exercise or not), the company accepts every customer order and tries to meet this demand by minimizing related costs. To summarize, the company would only exercise the option if the payoff using ondemand production capacity were greater than the payoff without using on-demand production capacity:

$$
R\left(T_{i}\right)-\mathrm{TPC}_{\mathrm{Ex}}>R\left(T_{i}\right)-\mathrm{TPC}_{\mathrm{NoEx}}
$$

From this equation, we can determine that the company only exercises the corresponding expansion option for $\mathrm{TPC}_{\mathrm{NoEx}}>\mathrm{TPC}_{\mathrm{Ex}}$. Hence, at time $T_{i}$, the value of the expansion option $C_{T_{i}}\left(T_{i}\right)$ equals the following:

$$
C_{T_{i}}\left(T_{i}\right)=\max \left\{T P C_{\mathrm{NoEx}}-T P C_{\mathrm{Ex}} ; 0\right\}
$$

For the computation of $\mathrm{TPC}_{\mathrm{Ex}}$ and $\mathrm{TPC}_{\mathrm{NoEx}}$, we must differentiate between two cases: $\bar{R} \geq \underline{R}$ and $\bar{R} \leq \underline{R}$. This is because the relationship between these two 
parameters critically influences the company's decision problem (cf. Table 1). As $\bar{R}$ is determined by the focal company and $\underline{R}$ by the ECP's business model, both cases can occur. Depending on $R\left(T_{i}\right), \bar{R}, \underline{R}, k_{\mathrm{int}}, k_{\mathrm{ext}}$, and $k_{\mathrm{dis}}$, the company can then determine the proportion of the revenue that should be produced in-house or by the ECP.

In cases I.1 and I.2, $R\left(T_{i}\right)$ is lower than or equal to $\underline{R}$ and $\bar{R}$. If the company does exercise the expansion option in these cases, it cannot, or will only just, meet the required MCS with its customer demand, and will simultaneously fail to utilize its internal production capacity (i.e., it outsources customer demand for increased production costs of $k_{\text {ext }}>k_{\text {int }}$ ). Conversely, even if the company does not exercise the expansion option, its internal production capacity is sufficient to avoid dissatisfied customers. This is to say that seizing on-demand production capacity would increase total production costs, and can, therefore, never be profitable $\left(T P C_{N o E x}-T P C_{E x}<0\right)$. The same applies in case II.1: As internal production capacity is still sufficiently large, outsourcing production for $k_{\text {ext }}>k_{\text {int }}$ can never be profitable. In case II.2, seizing on-demand production capacity can be profitable if the disadvantage of not or only just meeting the required MCS — and therefore (due to outsourcing) not utilizing internal production capacity-is overcompensated for by the advantage of avoiding dissatisfied customers (which would occur without the ECP). In cases III.1 and III.2, the profitability of exercising the expansion option further increases, as the company meets the required MCS with its customer demand. However, for $\left(T_{i}\right)<\underline{R}+\overline{\mathrm{R}}$, the company cannot exercise the expansion option and simultaneously utilize all of its internal production capacity, which is a disadvantage that can still exceed the monetary benefits of avoiding dissatisfied customers. For increasing $R\left(T_{i}\right)$ until $R\left(T_{i}\right)=\underline{R}+\bar{R}$ (upper interval boundary in cases III.1 and III.2), this disadvantage (and therefore, the cost of activating the external service) shrinks to zero. Exercising the expansion option in cases IV.1 and IV.2 $\left(\underline{R}+\bar{R} \leq R\left(T_{i}\right)\right)$ is always profitable, since the total internal production capacity is utilized and $k_{\mathrm{dis}}>k_{\mathrm{ext}}$. Thereby, the company can fully meet the required MCS. As using on-demand production capacity is not obligatory, the company would only exercise the option for $\mathrm{TPC}_{\mathrm{NoEx}}-\mathrm{TPC}_{\mathrm{Ex}} \geq 0$.

Figure 3 schematically illustrates the payoff $\mathrm{TPC}_{\mathrm{NoEx}}-\mathrm{TPC}_{\mathrm{Ex}}$ and the resulting real option values at time $t_{i}=T_{i}$. In Fig. $3 \mathrm{~b}$, i.e., for $\bar{R} \leq \underline{R}$, we illustrate two cases which can occur depending on parameter values (Cases II.2 and III.2 in Table 1 yield two possible payoff progressions depending on whether exercising the expansion option is profitable, i.e., "at the money", for $R\left(T_{i}\right) \leq \underline{R}$ or $\underline{R} \leq R\left(T_{i}\right)$ ).

\subsubsection{Valuation of the expansion option}

When entering a framework contract with the ECP, the company has $n$ independent expansion options; whereas, the duration of the $i \in n$th expansion option equals $i$ periods. As the company can exercise each option only once at the respective maturity date, we can apply the established option pricing for European call options. Thereby, $R\left(t_{i}\right)$ is the underlying of our expansion option, since its stochastic development directly affects the expansion option's value. We modify and apply the 


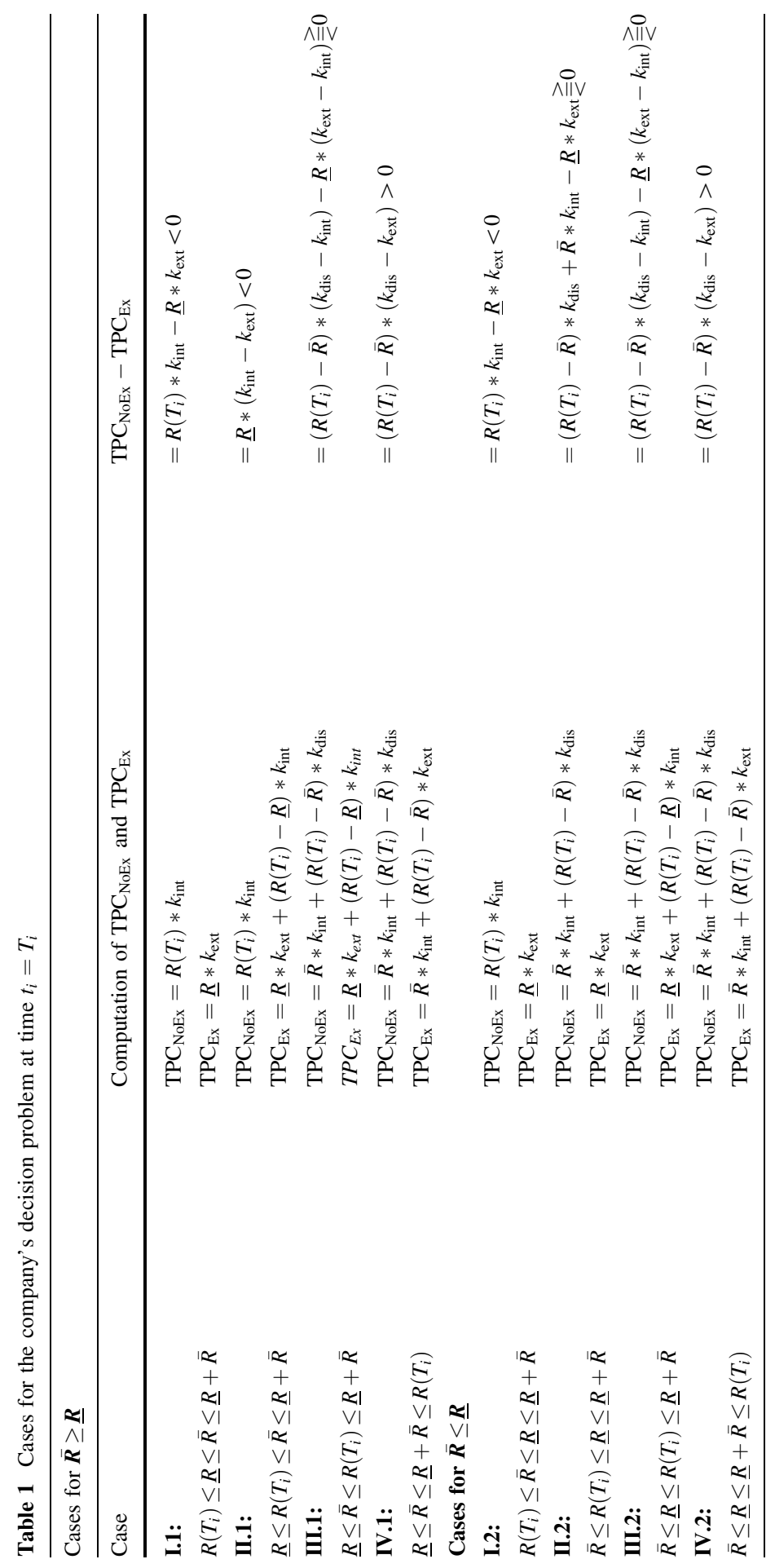




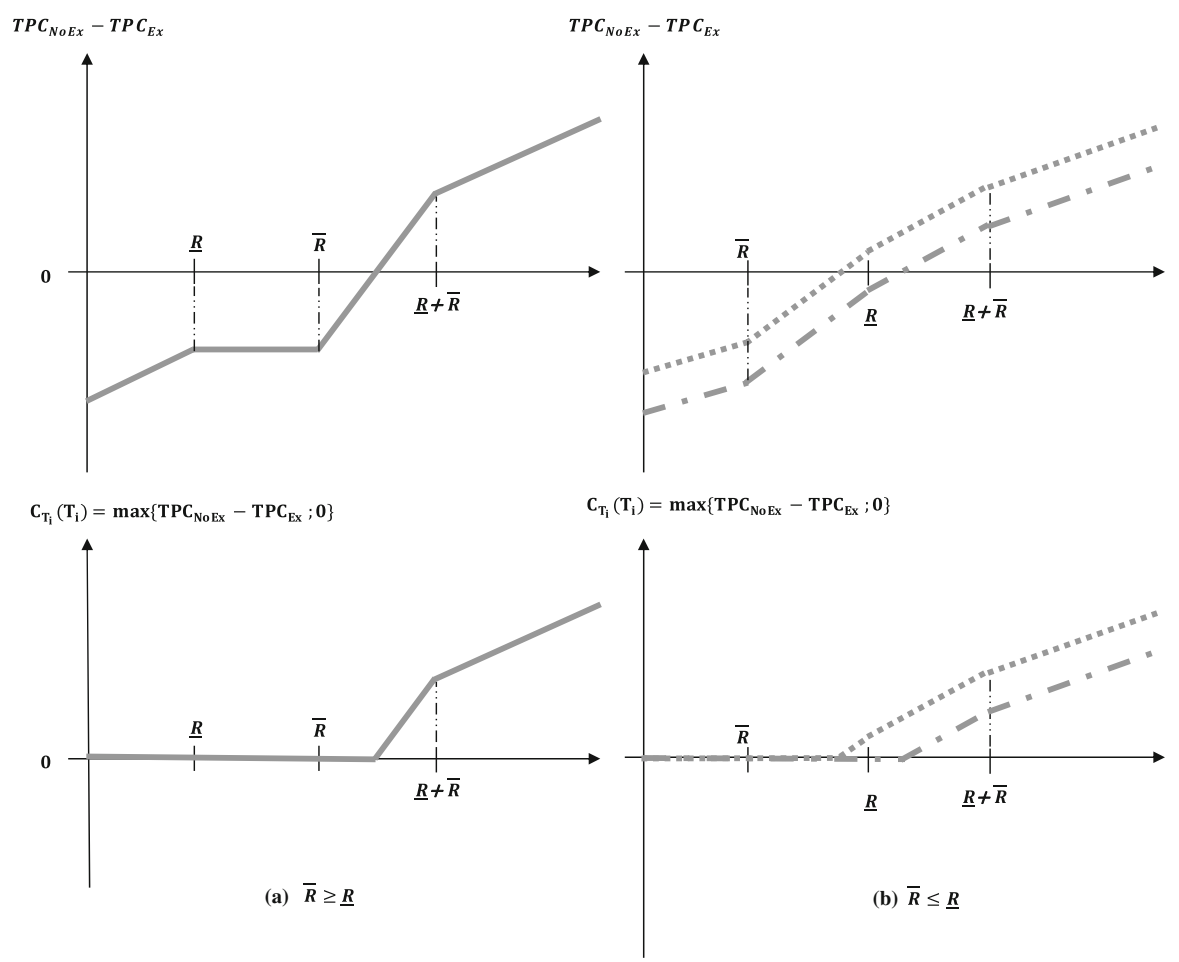

Fig. 3 Cash flows for option exercise at time $t_{i}=T_{i}$ for $\bar{R} \geq \underline{R}$ and $\bar{R} \leq \underline{R}$

binomial tree model of Cox et al. (1979), which enables the risk-neutral evaluation of European call options. Binomial tree models are one of the most commonly used methods for option evaluation as they are easy to comprehend and easy to adapt to customized input parameters (Copeland and Tufano 2004). In particular, we choose this discrete-time approach rather than a continuous-time approach, since the latter would exhibit increased mathematical complexity which may limit applicability for practitioners (Hauschild and Reimsbach 2015).

Since we assume risk-neutral decision-making (Assumption 6), we can apply formulae of Cox et al. (1979) to model the stochastic development of the company's total periodical revenue $R\left(t_{i}\right)$ :

$$
u=e^{\sigma * \sqrt{\Delta t}}, \quad d=e^{-\sigma * \sqrt{\Delta t}}, \quad p=\frac{\left(1+r_{f}\right)^{\Delta t}-d}{u-d} .
$$

As mentioned above, $u>1$ and $d<1$ are factors influencing the extent of $R\left(t_{i}\right)^{\prime} \mathrm{s}$ upward and downward movement within a single time increment. $p[1-p]$ is the probability of $R\left(t_{i}\right)$ moving upward [downward] within the next period. $r_{f}$ is the risk-free interest rate. In addition, Cox et al. (1979) introduce a necessary inequality: $d<1+r_{f}<u$ (no-arbitrage assumption). Following Cox et al. (1979), we can now determine the value of the company's expansion options. As we consider $n$ to represent independent expansion options, which are indicated using $i \in[1, n]$, we 
separately evaluate each expansion option $i$ by computing $C_{0, T_{i}}$ and then total these values to weigh them against cash outflows for upfront investments (Eq. 1). Thus, for each expansion option $i$, we model the binomial tree from $t_{i}=t_{0}$ to $t_{i}=T_{i}$ as illustrated in Fig. 2. Then, in the reverse direction, i.e., from end nodes at the respective maturity date $t_{i}=T_{i}$ to root $t_{0}$, we conduct option evaluation. More precisely, for expansion option $i$, we start option evaluation by determining the option value $C_{T_{i}}\left(t_{i}\right)$ in $t_{i}=T_{i}$ according to Eq. 3 .

As the binomial tree possesses $i+1$ end nodes in $T_{i}$, we must compute $i+1$ different values for $C_{T_{i}}\left(T_{i}\right)$ (which we differentiate by applying filtrations as introduced in Sect. 3.3.1). Since $R\left(t_{i}\right)$ is the only stochastic variable in our model, the subtraction of each end node $T P C_{N o E x}-T P C_{E x}$ depends only on this variable.

To determine the value of the expansion option from the perspective of $t_{0}$, i.e., $C_{T_{i}}\left(t_{0}\right)$, we must compute the probability-weighted average of all $C_{T_{i}}\left(T_{i}\right)$ and discount them to the present. Reintroducing the filtration notation, Fig. 4 illustrates an example with three periods.

For example, the probability of $C_{T_{i}, W_{t_{2}, 1}}\left(t_{3}\right)$ equals $p\left(C_{T_{i}, W_{t_{2}, 1}}\left(t_{3}\right)\right)=p^{3}$. Considering all end nodes $s \in\{1, \ldots, i+1\}$ in the tree, we can compute the value of the expansion option in $t_{0}$ :

$$
C_{T_{i}}\left(t_{0}\right)=\frac{\sum_{s} p\left(C_{T_{i}, W_{t_{i-1}, s}}\left(T_{i}\right)\right) * C_{T_{i}, W_{t_{i-1}, s}}\left(T_{i}\right)}{\left(1+r_{f}\right)^{T_{i}}}
$$

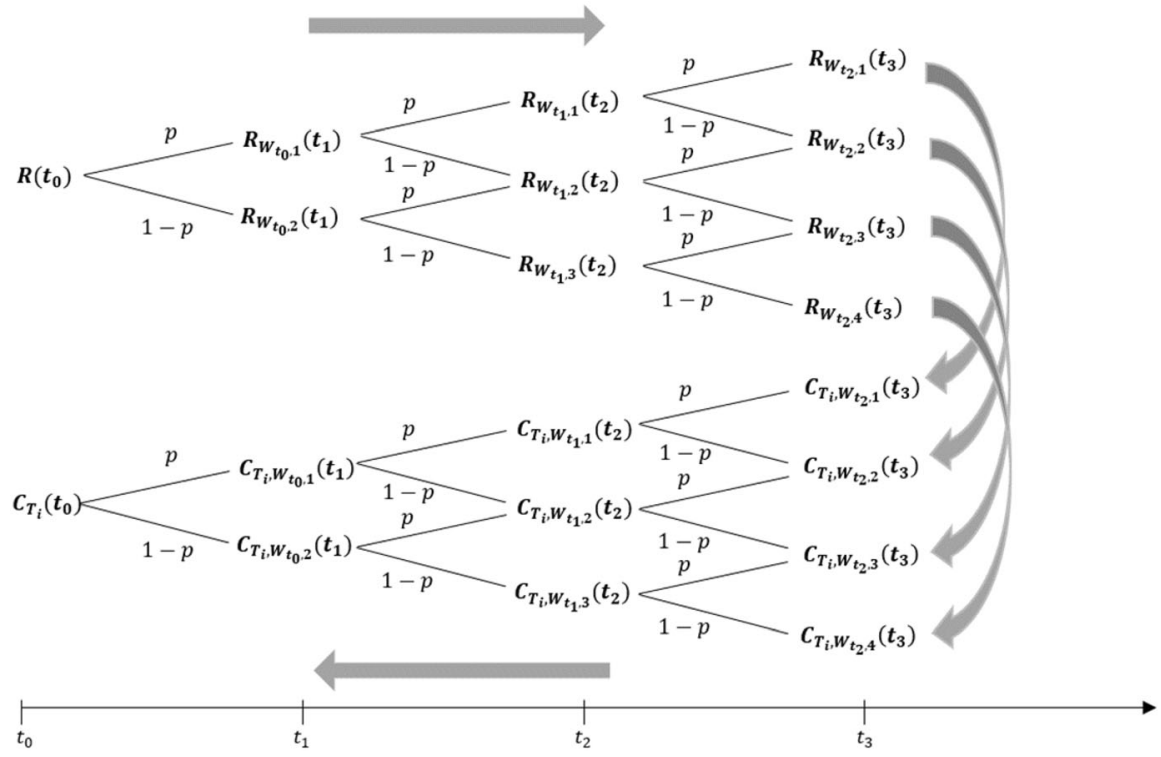

Fig. 4 Binomial tree model for option evaluation 
This procedure must be reiterated for every expansion option $i \in[1, n]$. Once this task has been completed, we use Eq. 1 to evaluate the company's overall business case $V_{0}$.

As we illustrate in Sect. 2, ROA is widely applied in investment decision analysis. However, as we adapt option pricing from financial option evaluation, we must analyze the original requirements for the valid application of this method. Unfortunately, this analysis has been neglected by many other authors applying ROA (Ullrich 2013). Firstly, following Ullrich (2013), one requirement for the valid application of traditional option pricing models is a strike price that is constant or modeled for its stochastic nature. Within our ROA, we do not explicitly model a strike price which is implicitly part of the subtraction $\mathrm{TPC}_{\mathrm{NoEx}}-\mathrm{TPC}_{\mathrm{Ex}}$. However, if we were to aggregate all constant cost factors in each of the cases presented in Table 1, this would equal a formal representation of the strike price. As a result, we would find that the strike price is only constant within each of the cases but not between different cases. Hence, to validly compute the value of the expansion option, our approach must take the stochastic nature of the strike price into consideration. We meet this requirement: as the strike price is case specific, it only depends on one stochastic variable, which is $R\left(t_{i}\right)$. Therefore, for each end node in $R\left(t_{i}\right)$ 's binomial tree, we obtain exactly one value for the strike price of the expansion option. Hence, our approach to ROA is valid in this respect. Secondly, we confirm that each expansion option can be exercised only once at its maturity date. The option's term is already specified when the company makes a decision about signing the framework contract. Thirdly, the value of the underlying must evolve according to a Geometric Brownian Motion (GBM) and exhibit a constant variance. This requirement of a GBM originally refers to continuous-time models. In our discrete-time model, the underlying must, therefore, evolve according to a multiplicative binomial diffusion process which converges (for decreasing-length time increments) to a GBM (Benaroch and Kauffman 1999). Due to Assumption 1, both requirements apply in the case of the company's total periodical revenue $R\left(t_{i}\right)$. Fourthly, for financial options, there must exist a "complete market" that allows continuous trading of both the underlying and the option. As ROA evaluates flexibility of action, this requirement does not usually apply to either the underlying or the option. This is a long-standing problem in ROA literature, and we follow Benaroch and Kauffman (1999) who refer to Mason and Merton (1985) in stating that "irrespective of whether a project is traded, we seek to determine what the project cashflows would be worth if they were traded" (p. 77).

\section{Evaluation of the model}

In this section, we demonstrate how our model can be applied to evaluate upfront investments in flexible on-demand production capacity. We begin by presenting a set of freely selected scenario parameters. As manually selected parameters are biased in their validity, we subsequently conduct randomly chosen simulations and sensitivity analyses to demonstrate the robustness of our model. 


\subsection{Basic case}

As stated in Sect. 3.1, we use the example of a company that manufactures a single but individualized product using an MTO approach. Seeking to increase volume flexibility, the company considers commissioning an ECP that offers flexible ondemand production capacity. The company calculates that accessing such ondemand production capacity will require an upfront investment of $I_{0}=\$ 300,000$ for availability guarantees and the necessary IS infrastructure. Regarding Eq. 1, we assume this to be the entirety of cash outflows for upfront investments. The company would enter a 12-month framework contract with the ECP. The contract specifies that the company has the option to decide the on-demand production capacity at the end of every month, meaning that the company will obtain 12 expansion options. Independent of this opportunity, the company's own internal production capacity enables it to process a constant maximum revenue of $\bar{R}=$ $\$ 1,000,000$ per month. The ratio of internal production costs to customer revenue equals $k_{\text {int }}=0.7$, and the company's total periodic revenue for the current month $R\left(t_{0}\right)=\$ 1,000,000$. These figures are used for future revenue predictions. By analyzing historical data, the company estimates that the monthly volatility of $R\left(t_{i}\right)$ will equal $15 \%$, i.e., $\sigma=0.15$. If customer demand cannot be satisfied, the company estimates costs for dissatisfied customers to a proportion of $k_{\mathrm{dis}}=1.1$ of customer revenue, i.e., due to the loss of customer lifetime value and order cancellations, the company incurs costs exceeding the revenue of a single MTO product. Entering the framework contract with the ECP would enable outsourcing. In the contract, the ECP specifies a minimum contract size of $\mathrm{MCS}=\$ 400,000$ for each option exercised, with external production costs to a proportion of $k_{\mathrm{ext}}=0.8$ of customer revenue. Hence, due to MCS $=\underline{R} * k_{\text {ext }}$, the company's revenue from its customers that yields the required MCS equals $\underline{R}=\$ 500,000$. Using this information, the company can apply our approach for ROA to quantify the value of flexible ondemand production capacity, and then decide whether to make the required initial upfront investment. Assuming an annual risk-free interest rate $r_{f}=0.7 \%^{2}$ for riskneutral evaluation, we obtain the results illustrated in and below Fig. 5:

- Value of expansion options $\sum_{i=1}^{12} C_{T_{i}}\left(t_{0}\right)=\$ 541,091$

- Upfront investments $I_{0}=\$ 300,000$

- Business case value $V_{0}=\$ 241,091$

Since the overall business case has a monetary value greater than zero, the company should make the upfront investment and enter the framework contract with the ECP.

\footnotetext{
${ }^{2} r_{f}=0.7 \%$ is the mean of the 3-month U.S. Treasury Bill yields observed over the last 10 years (Mukherji 2011; U.S. Department of the Treasury 2017).
} 


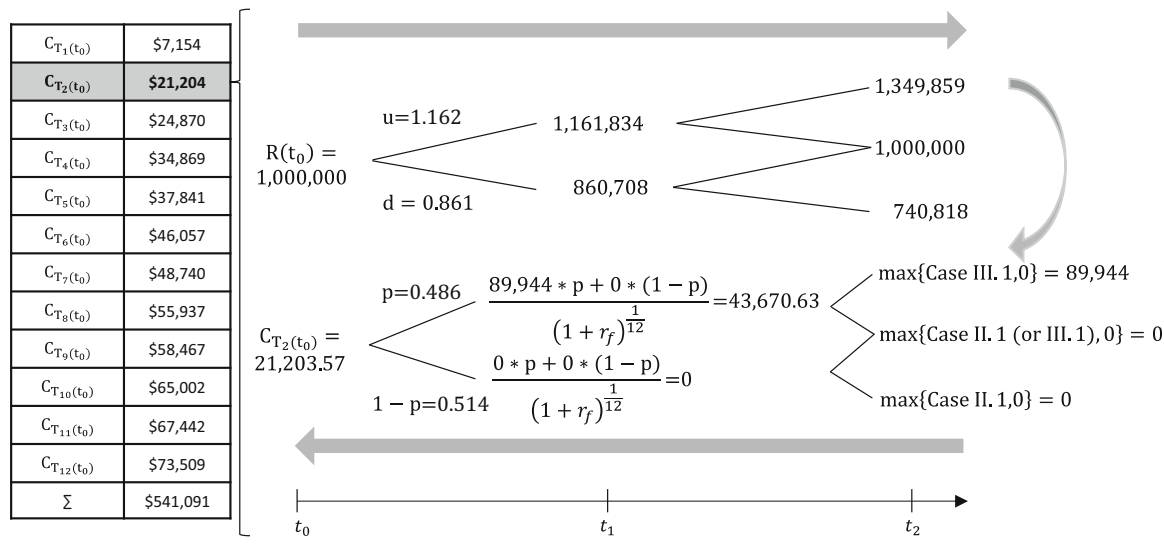

Fig. 5 Option Values in $\boldsymbol{t}_{0}$ and exemplary computation for $\boldsymbol{C}_{\boldsymbol{T}_{2}}\left(\boldsymbol{t}_{0}\right)$

\subsection{Simulation and sensitivity analyses}

\subsubsection{Simulation}

To demonstrate the robustness of our model, we conducted randomly chosen simulations and sensitivity analyses. For this purpose, we implemented our model using Microsoft Excel supported by Visual Basic for Application macros, and chose to draw uniformly distributed model parameters from the following intervals (we assume $\bar{R}$ and $k_{\text {int }}$ to be constant and to equal our basic case):

- Annual risk-free interest rate $\boldsymbol{r}_{f} \in[0 ; 0.052]$ :

We chose $5.2 \%$ as the upper interval boundary, since the maximum annual return on a 3-month U.S. Treasury Bill within the last 10 years amounted to $5.2 \%$ (Mukherji 2011; U.S. Department of the Treasury 2017).

- Volatility of total periodical revenue $\sigma \in\left[0.001+\ln \left(1+\boldsymbol{r}_{f}\right) ; 1\right]$ :

We chose this lower interval boundary for $\sigma$ due to the no-arbitrage condition in Cox et al. (1979)'s binomial tree model: $d<1+r_{f}<u$, i.e., $e^{-\sigma * \sqrt{\Delta t}}<1+r_{f}<e^{\sigma * \sqrt{\Delta t}}$. Solving this inequality for $\sigma$, we obtained $\sigma>\frac{\ln \left(1+r_{f}\right)}{\sqrt{\Delta t}}=$ $\ln \left(1+r_{f}\right)$ (with $\left.\Delta t=1\right)$. For the interval's upper boundary, we arbitrarily chose $\sigma=1$, i.e., a periodical volatility of $R\left(t_{0}\right)$ of $100 \%$.

- Initial month's total periodical revenue $\boldsymbol{R}\left(\boldsymbol{t}_{0}\right) \in[500,000 ; 1,500,000]$ :

We arbitrarily chose to draw $R\left(t_{0}\right)$ from a corridor around the base case's $\bar{R}$.

- External production costs per unit $\boldsymbol{k}_{\text {ext }}=0.7 *(1.001+\boldsymbol{q}), \boldsymbol{q} \in[0,0.5]$ :

Assumption 4 argues that $k_{\text {int }}$ must be lower than $k_{\text {ext }}$. Therefore, we scaled $k_{\text {ext }}$ with a randomly chosen surcharge of up to $50 \%$ of $k_{\text {int }}=0.7$. 
- Production costs per unit for dissatisfied customers $\boldsymbol{k}_{\text {dis }}=\boldsymbol{k}_{\text {ext }} *(1.001+\boldsymbol{p}), \boldsymbol{p} \in[0,0.5]$ :

Assumption 4 argues that $k_{\text {ext }}$ must be lower than $k_{\text {dis }}$. Therefore, we scaled $k_{\text {dis }}$ with a randomly chosen surcharge of up to $50 \%$ of $k_{\text {ext }}$.

- Contract term $\boldsymbol{T}_{\boldsymbol{n}} \in[1 ; 24]$ :

We arbitrarily chose contract terms between 1 and 24 months. Each month equals one real option.

- Minimum contract size $\operatorname{MCS} \in[0 ; 1,000,000]$ :

We arbitrarily chose to draw MCS from a corridor around the base case's MCS.

Due to the many possible parameter combinations, we repeated our simulation 300,000 times to produce high-quality sensitivity analyses. For each simulation we ran, our algorithm drew input parameters according to the intervals presented, and calculated the value of real options. Accounting for all simulations, we achieved the results depicted in Fig. 6.

Within our simulation, the aggregated values of expansion options $\sum_{i=1}^{n} C_{0, T_{i}}$ vary between zero and $\$ 15,485,424$. Although we observe a long tail that we aggregated in Fig. 6 for values greater than $\$ 8,000,000$, approximately $55 \%$ of simulation runs yielded values between $\$] 0 ; 1,000,000]$. In only $5 \%$ of all simulation runs the aggregated value of expansion options is zero, i.e., in $95 \%$ of all simulation runs, the aggregated value of expansion options is positive and, thus, would help to amortize initial upfront investments. Results of our simulation indicate that volume flexibility using on-demand production capacity from an ECP is of considerable value to manufacturing companies.

\subsubsection{Sensitivity analyses}

To provide further analysis, we depict sensitivities to our results in Fig. 7. To do so, we apply sensitivity analyses according to the famous quantities "Greeks" to verify the validity of our model in terms of common option pricing theory. In particular, we analyze the univariate sensitivities of expansion option values to their contract term $T_{n}$ ("Theta"), the annual risk-free interest rate $r_{f}$ ("Rho"), and the volatility of the total periodical revenue $\sigma$ ("Vega"). In addition to the "Greeks", we analyze univariate sensitivity to MCS, $R\left(t_{0}\right), k_{\text {ext }}$, and $k_{d i s}$, as these were factors that varied in our simulation.

The sensitivity analyzes we conducted regarding the "Greeks" reveal the following insights about the robustness of our model:

- Firstly, Theta (Fig. 7a) illustrates that the expansion option values increase with longer contract terms $T_{n}$. Longer contract terms are synonymous with larger numbers of expansion options, all of which possess a value greater than or equal to zero.

- Secondly, Rho (Fig. 7b) illustrates that the expansion option values slightly increase with a greater risk-free interest rate $r_{f}$. A greater risk-free interest rate 


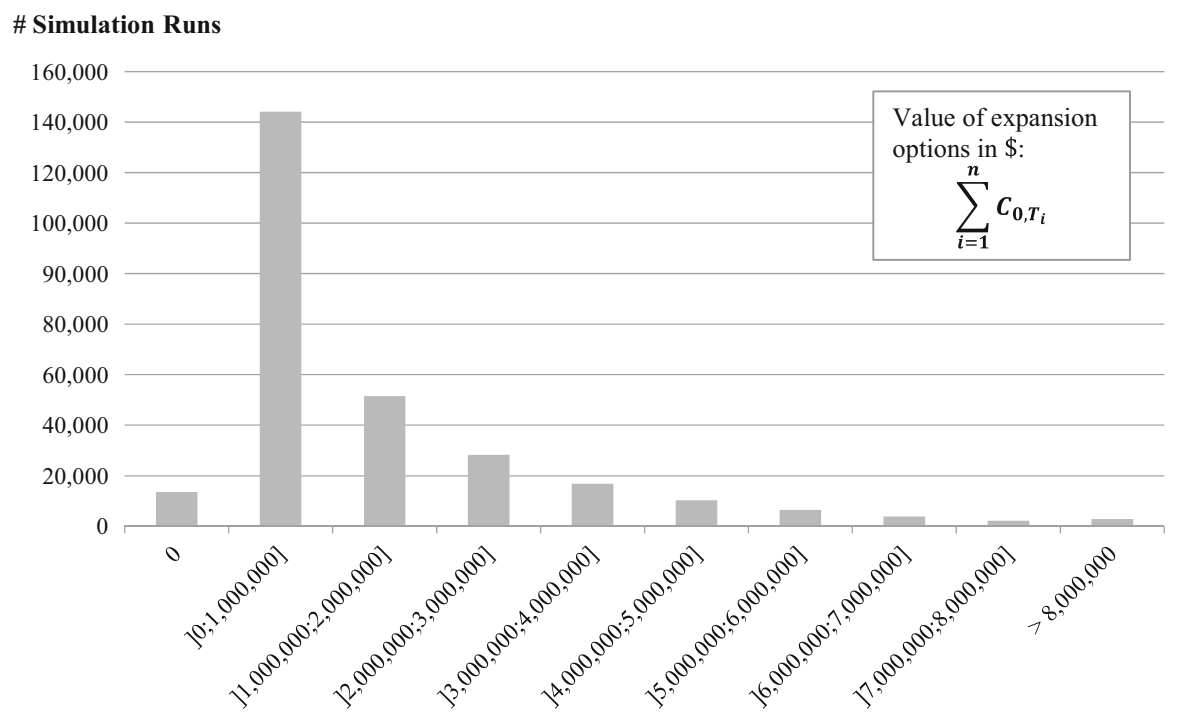

Fig. 6 Histogram with absolute simulation results

increases the company's monetary advantage in that it does not have to pay for additional production capacity until the expiration dates of the expansion options.

- Thirdly, Vega (Fig. 7c) illustrates that the expansion option values increase along with the volatility of the company's total periodical revenue $\sigma$. Without on-demand production capacity, a greater volatility in the company's total periodical revenue implies that there will be more dissatisfied customers, leading to corresponding costs of $k_{\mathrm{dis}}$, or idle costs in case of unused capacity. A framework contract with the ECP, however, allows the company the flexibility to react to uncertainties in the development of demand.

We conducted statistical two-sample t-tests which confirm this observation (significance levels: $0.1 \%$ for Theta and Vega and 5\% for Rho). All three observations are in line with common option pricing theory for European call options (Hull and White 1987).

The sensitivity analysis of expansion option values to minimum contract size MCS (Fig. 7d) illustrates that expansion option values decrease for greater MCS. A greater MCS increases fixed costs for the exercise of expansion options and, therefore, decreases their values. We conducted another statistical two-sample $t$ test which confirms this observation (significance level: $0.1 \%$ ). The sensitivity analysis of the expansion option values to the initial month's customer revenue $R\left(t_{0}\right)$ illustrates that expansion option values increase with greater $R\left(t_{0}\right)$ (significance level: $0.1 \%$ ). As a greater $R\left(t_{0}\right)$ also indicates greater values of the total periodical revenue in future, the probability of a decrease in total production costs as a result of the use of on-demand production capacity is also increasing (remember, internal production capacity is assumed to be constant). In addition, a sensitivity analysis of 


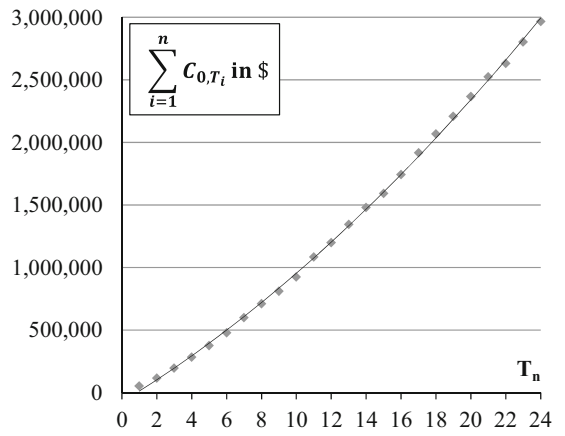

(a) Contract duration $T_{n}$

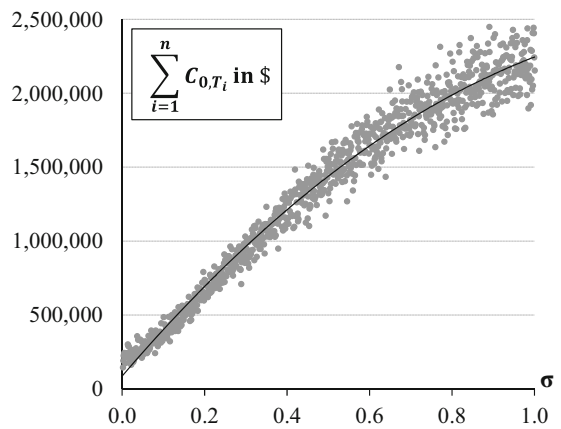

(c) Volatility $\sigma$

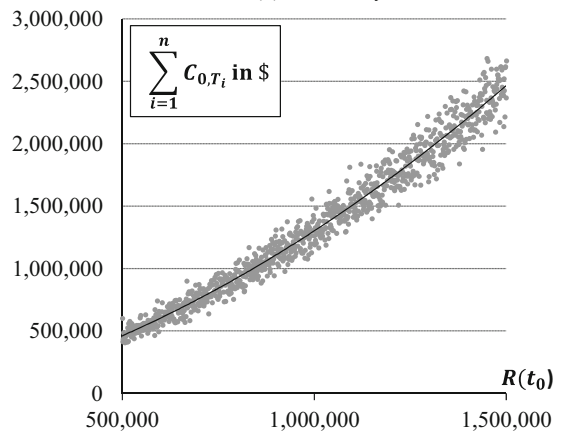

(e) Initial month's customer revenue $R\left(t_{0}\right)$

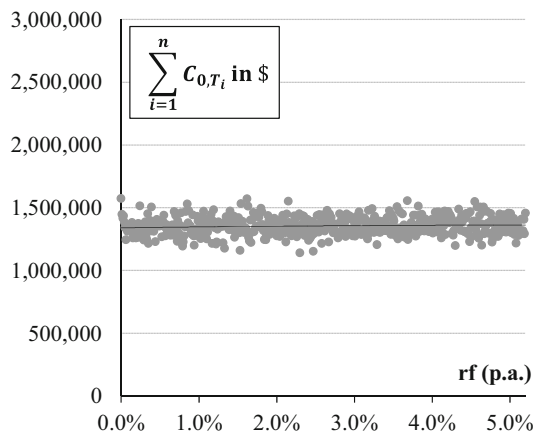

(b) Risk-free interest rate $r_{f}$

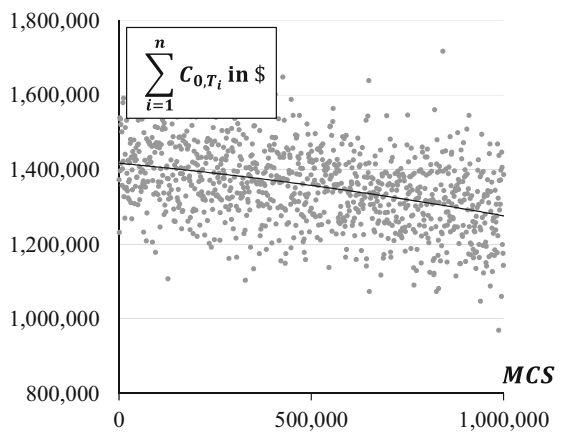

(d) Minimum contract size MCS

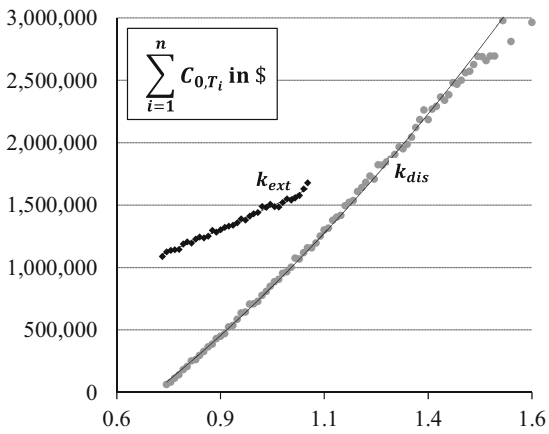

(f) Ext. production costs $k_{\text {ext }}$ and costs of dissatisfied customers $k_{\text {dis }}$

Fig. 7 Sensitivity analyses

expansion option values to $k_{\text {ext }}$ and $k_{\text {dis }}$ illustrates that expansion option values increase for greater $k_{\text {ext }}$ and $k_{\text {dis }}$ (significance levels: $0.1 \%$ for both factors). For $k_{\text {dis }}$, this observation is intuitive. Without the ECP, a greater $k_{\text {dis }}$ significantly increases costs due to dissatisfied customers, and the company may even incur costs exceeding the revenue of a single MTO product. Inversely, on-demand production capacity is an insurance against such costs and increases the value of expansion 
options. For $k_{\text {ext }}$, however, this observation may not seem intuitive, as greater costs for outsourcing should not favor the value of on-demand production capacity. We attribute this observation to our parameter selection, as the draw of $k_{\text {dis }}$ depends on $k_{\text {ext }}$. As $k_{\text {dis }}$ exceeds $k_{\text {ext }}$ based on a multiplicative factor greater than one, the (positive) effect of greater $k_{\mathrm{dis}}$ on the value of expansion options exceeds the (negative) effect of greater $k_{\text {ext }}$ on expansion option values. This technical limitation of our simulation (that is, the interdependence of both factors) is necessary to guarantee $k_{\mathrm{dis}}>k_{\mathrm{ext}}>k_{\text {int }}$.

\section{Implications}

Our results enable us to draw insights relevant to both researchers and practitioners. For researchers, particularly those working in the field of investment decision theory, we provide a methodological contribution: Our approach illustrates how a decision-maker can (i) model an industrial company's use of the on-demand production capacity offered by an ECP, accounting for several expansion options; (ii) evaluate the corresponding volume flexibility; and (iii) evaluate the upfront investments which enable the use of flexible on-demand production capacity, taking into consideration the value of different expansion options. Our approach can be classed as formal, as we identify important requirements for the valid application of ROA (Ullrich 2013) and demonstrate that the sensitivity of our results to model parameters mirror findings from common option pricing theory ("Greeks").

For practitioners, our results demonstrate that the opportunity to seize on-demand production capacity can be of considerable value to industrial companies, especially when working with longer framework contracts. Therefore, companies should investigate whether additional volume flexibility is an appropriate means of reducing the adverse effects of volatile customer demand and production costs. According to our results, on-demand production capacity seems particularly promising for companies in fast-moving industries which exhibit rapidly changing customer preferences and, therefore, highly volatile customer demand (e.g., the consumer electronics industry). In addition, volume flexibility is particularly promising for companies with limited investment budgets, such as SMEs, and during periods of high interest rates, as companies can defer their investments in internal production capacity. Practitioners who are responsible for production capacity planning can use our ROA approach to evaluate volume flexibility and decide on necessary upfront investments within an ENPV approach. Moreover, they can use a respective business case for comparison with other business opportunities such as investments in the expansion of internal production capacity. Practitioners from ECPs can use our approach for the parametrization of their business models, and for marketing and sales purposes to support potential customers in their business case evaluation. 


\section{Conclusion, limitations, and further research}

Shorter product life cycles due to technological progress and changing customer preferences, along with customers' desire for the instant availability of highly individualized products, yield increasingly volatile levels of customer demand, which complicate the production capacity planning of industrial companies. Aside from investments in new production facilities or customer order-controlling approaches such as revenue management, companies can make use of volume flexibility using the on-demand production capacity provided by ECPs. However, the dynamic integration of on-demand production capacity may require companies to make substantial upfront investments, which they must evaluate in an appropriate manner, i.e., in line with the principles of value-based management. In this paper, we present an ENPV approach that enables such an appropriate evaluation of necessary upfront investments, taking into account flexibility of action and demand uncertainty. To model flexible access to on-demand production capacity and demand uncertainty, we apply ROA using binomial tree evaluation of Cox et al. (1979). We evaluate our model using a simulation and sensitivity analyses, and conclude that, in approximately $95 \%$ of all simulation runs, the value of the expansion options, i.e., the value of volume flexibility, is positive.

However, our approach has some limitations which give rise to future research opportunities. For reasons of complexity reduction, we assume that the industrial company can take on an infinite level of on-demand production capacity. Moreover, we set internal and external production costs at a constant level over the planning horizon and do not account for changing costs due to macro-economic or market developments, or for further product life-cycle costs, which are also important to consider (Lukas et al. 2017). In applying formulae of Cox et al. (1979), we use a multiplicative (stochastic) binomial process of the company's total periodical revenue to describe uncertainty, which significantly influences the choice of internal and external production scheduling. However, this may not necessarily hold true in practice as the development of this stochastic variable may not exhibit normally distributed returns with a constant mean and volatility. Therefore, future research could, for example, apply fat tail distributions. Moreover, researching continuous-time approaches for ROA could enable continuous-time evaluation. Since the provision of on-demand production capacity represents a new business model that lacks widespread in practice, our simulation parameters are not based on real-world data. Therefore, an appropriate next step would be to evaluate our model using a real-world example. By applying an ENPV method, we aim to evaluate investments in new technologies which enable volume flexibility using on-demand production capacity. Nevertheless, these investments could also lead to further benefits, such as improved process efficiency, which are not considered in our model. Consequently, there may be more benefits which could be considered in future research and integrated in a holistic evaluation model of investments in digital transformation. However, our current approach is a first step in this direction, and provides both researchers and practitioners with valuable insights which can be built upon in the future. 
Open Access This article is distributed under the terms of the Creative Commons Attribution 4.0 International License (http://creativecommons.org/licenses/by/4.0/), which permits unrestricted use, distribution, and reproduction in any medium, provided you give appropriate credit to the original author(s) and the source, provide a link to the Creative Commons license, and indicate if changes were made.

\section{References}

Abel, Andrew B., Avinash K. Dixit, Janice C. Eberly, and Robert S. Pindyck. 1996. Options, the value of capital, and investment. The Quarterly Journal of Economics 111 (3): 753-777.

Akşin, O.Zeynep, Francis de Véricourt, and Fikri Karaesmen. 2008. Call center outsourcing contract analysis and choice. Management Science 54 (2): 354-368.

Alaniazar, Saman. 2013. Demand modeling and capacity planning for innovative short life-cycle products, Wayne State University Dissertations.

Amram, Martha, and Nalin Kulatilaka. 1998. Real options: Managing strategic investment in an uncertain world. Boston: Harvard Business School Press.

Benaroch, Michel, and Robert J. Kauffman. 1999. A case for using real options pricing analysis to evaluate information technology project investments. Information Systems Research 10 (1): 70-86.

Benaroch, Michel, Qizhi Dai, and Robert J. Kauffman. 2010. Should we go our own way? Backsourcing flexibility in IT services contracts. Journal of Management Information Systems 26 (4): 317-358.

Benaroch, Michel, and Robert J. Kauffman. 2000. Justifying electronic banking network expansion using real options analysis. MIS Quarterly 24 (2): 197-225.

Benavides, Dario L., James R. Duley, and Blake E. Johnson. 1999. As good as it gets: Optimal fab design and deployment. IEEE Transactions on Semiconductor Manufacturing 12 (3): 281-287.

Black, Fischer, and Myron Scholes. 1973. The pricing of options and corporate liabilities. Journal of political economy 81 (3): 637-654.

Boulaksil, Youssef, and Jan C. Fransoo. 2010. Implications of outsourcing on operations planning: Findings from the pharmaceutical industry. International Journal of Operations \& Production Management 30 (10): 1059-1079.

Brettel, Malte, Niklas Friederichsen, Michael Keller, and Marius Rosenberg. 2014. How virtualization, decentralization and network building change the manufacturing landscape: An industry 4.0 perspective. International Journal of Mechanical, Industrial Science and Engineering, 8 (1): 37-44.

Chase, Richard B., Nicholas J. Aquilano, and F. Robert Jacobs. 2004. Operations management for competitive advantage, 10th ed. Boston: Irwin/McGraw-Hill.

Chen, Ruey-Shun, Lu Kun-Yung, Yu. Shien-Chiang, Hong-Wei Tzeng, and C.C. Chang. 2003. A case study in the design of BTO/CTO shop floor control system. Information \& Management 41 (1): 25-37.

Copeland, Thomas E., and Vladimir Antikarov. 2003. Real options: A practitioner's guide. New York: Texere.

Copeland, Tom, and Peter Tufano. 2004. A real-world way to manage real options. Harvard Business Review 82 (3): 90-99.

Cox, John C., Stephen A. Ross, and Mark Rubinstein. 1979. Option pricing: A simplified approach. Journal of Financial Economics 7 (3): 229-263.

Dangl, Thomas. 1999. Investment and capacity choice under uncertain demand. European Journal of Operational Research 117 (3): 415-428.

Dong, Lingxiu, and Erik Durbin. 2005. Markets for surplus components with a strategic supplier. Naval Research Logistics (NRL) 52 (8): 734-753.

Dorsch, Christoph and Björn Häckel. 2012. Matching economic efficiency and environmental sustainability: The potential of exchanging excess capacity in cloud service environments. Proceedings of the Thirty-Third International Conference on Information Systems. ICIS, Orlando, Florida, USA.

Dorsch, Christoph, and Björn Häckel. 2014. Combining models of capacity supply to handle volatile demand: The economic impact of surplus capacity in cloud service environments. Decision Support Systems 58: 3-14.

eMachineShop. 2017. The World's Longest Established Online Machine Shop. https://www. emachineshop.com/about-emachineshop/. Accessed 23 November 2017. 
EMAG. 2017. ServicePlus Vermietung. http://www.emag.com/serviceplus/full-service/renting.html. Accessed 23 November 2017.

Fernandes, Rui, Borges Gouveia, and Carlos Pinho. 2012. Vertical integration moment in dynamic markets. Strategic Outsourcing: An International Journal 5 (2): 121-144.

Fichman, Robert G., Mark Keil, and Amrit Tiwana. 2005. Beyond valuation: "Options thinking” in IT project management. California Management Review 47 (2): 74-96.

Garrido, Fernando. 2012. This time it's personal: from consumer to co-creator. http://www.ey.com/ Publication/vwLUAssets/This_time_its_personal/\$FILE/AS\%20Customer\%20Barometer\% 20This\%20Time\%20Its\%20Personal\%20FINAL.pdf. Accessed 25 November 2017.

Gerhard, Detlef. 2017. Product Lifecycle Management Challenges of CPPS, eds. Stefan Biffl, Arndt Lüder, and Detlef Gerhard. In Multi-Disciplinary Engineering for Cyber-Physical Production Systems: Data Models and Software Solutions for Handling Complex Engineering Projects, Cham: Springer, pp. 89-110.

Haruvy, Ernan, Elena Katok, Zhongwen Ma, and Suresh Sethi. 2018. Relationship-specific investment and hold-up problems in supply chains: Theory and experiments. Business Research.

Hauschild, Bastian, and Daniel Reimsbach. 2015. Modeling sequential R\&D investments: A binomial compound option approach. Business Research 8 (1): 39-59.

Hull, John, and Alan White. 1987. The pricing of options on assets with stochastic volatilities. The Journal of Finance 42 (2): 281-300.

Kagermann, Henning, Johannes Helbig, Ariane Hellinger, and Wolfgang Wahlster. 2013. Recommendations for implementing the strategic initiative INDUSTRIE 4.0: Securing the future of German manufacturing industry; final report of the Industrie 4.0 Working Group: Forschungsunion.

Katzmarzik, Arne, Matthias Henneberger, and Hans Ulrich Buhl. 2012. Interdependencies between automation and sourcing of business processes. Journal of Decision Systems 21 (4): 331-352.

Klaus, Carsten, Felix Krause, and Christian Ullrich. 2014. Determining the business value of volume flexibility for service providers-a real options approach. In: Proceedings of the 22nd European Conference on Information Systems, ECIS, Tel Aviv, Israel, June 2014.

Kleinert, Alexander, and Volker Stich. 2010. Valuation of procurement flexibility in the machinery and equipment industry using the real option approach. In Integration and Interoperability, ed. E. Architecture, 21-31. Berlin: Springer.

Kogut, Bruce, and Nalin Kulatilaka. 1994. Options thinking and platform investments: Investing in opportunity. California Management Review 36 (2): 52-71.

Kremic, Tibor, Oya Icmeli Tukel, and Walter O. Rom. 2006. Outsourcing decision support: A survey of benefits, risks, and decision factors. Supply Chain Management: An International Journal 11 (6): $467-482$.

Lankford, William M., and Faramarz Parsa. 1999. Outsourcing: A primer. Management Decision 37 (4): 310-316.

Lasi, Heiner, Peter Fettke, Hans-Georg Kemper, Thomas Feld, and Michael Hoffmann. 2014. Industry 4.0. Business \& Information Systems Engineering 6 (4): 239-242.

Lee, In, and Kyoochun Lee. 2015. The Internet of Things (IoT): Applications, investments, and challenges for enterprises. Business Horizons 58 (4): 431-440.

Lier, Stefan, Dominik Wörsdörfer, and Marcus Grünewald. 2012. Real options for economic assessments of innovation projects in chemical production. Chemie Ingenieur Technik 84 (12): 2164-2173.

Luehrman, Timothy A. 1998. Investment opportunities as real options: Getting started on the numbers. Harvard Business Review 76 (4): 51-67.

Lukas, Elmar, Thomas Stefan Spengler, Stefan Kupfer, and Karsten Kieckhäfer. 2017. When and how much to invest? Investment and capacity choice under product life cycle uncertainty. European Journal of Operational Research 260 (3): 1105-1114.

Mason, Scott P. and Robert C. Merton. 1985. The role of contingent claims analysis in corporate finance, eds. Edward I. Altman and Marti G. Subrahmanyam. In Recent Advances in Corporate Finance. Homewood, IL: Richard D. Irwin.

Matt, Dominik T., Erwin Rauch, and Patrick Dallasega. 2015. Trends towards distributed manufacturing systems and modern forms for their design. Procedia CIRP 33: 185-190.

Merton, Robert C. 1973. Theory of rational option pricing. Theory of Valuation, 229-288.

Monostori, László. 2014. Cyber-physical production systems: Roots, expectations and R\&D challenges. Procedia CIRP 17: 9-13. 
Mosig, Tim, Leontin Grafmüller, and Claudia Lehmann. 2017. Business model patterns of B2B Mass Customizers: The Case of German Textile SMEs. International Journal of Industrial Engineering and Management 8 (3): 99-110.

Mukherji, Sandip. 2011. The capital asset pricing model's risk-free rate. The International Journal of Business and Finance Research 5 (2): 75-83.

Myers, Stewart C. 1977. Determinants of corporate borrowing. Journal of Financial Economics 5 (2): $147-175$.

Myers, Stewart C. 1984. Finance theory and financial strategy. Interfaces 14 (1): 126-137.

Olhager, Jan, and Björn Östlund. 1990. An integrated push-pull manufacturing strategy. European Journal of Operational Research 45 (2-3): 135-142.

Panayi, Sylvia, and Lenos Trigeorgis. 1998. Multi-stage real options: The cases of information technology infrastructure and international bank expansion. The Quarterly Review of Economics and Finance 38 (3): 675-692.

Penas, Olivia, Régis Plateaux, Stanislao Patalano, and Moncef Hammadi. 2017. Multi-scale approach from mechatronic to cyber-physical systems for the design of manufacturing systems. Computers in Industry 86: 52-69.

Rauschecker, Ursula, Daniel Stock, Matthias Stöhr, and Alexander Verl. 2014. Connecting factories and related IT environments to manufacturing clouds. International Journal of Manufacturing Research 9 (4): 389-407.

Ren, Lei, Lin Zhang, Lihui Wang, Fei Tao, and Xudong Chai. 2017. Cloud manufacturing: Key characteristics and applications. International Journal of Computer Integrated Manufacturing 30 (6): 501-515.

Schwartz, Eduardo S. and Lenos Trigeorgis. 2004. Real options and investment under uncertainty: An overview, eds. Eduardo S. Schwartz and Lenos Trigeorgis. In Real options and investment under uncertainty: Classical readings and recent contributions, 1-18: MIT Press.

Spath, Dieter, Oliver Ganschar, Stefan Gerlach, Moritz Hämmerle, Tobias Krause, and Sebastian Schlund. 2013. Produktionsarbeit der Zukunft-Industrie 4.0: Fraunhofer Verlag Stuttgart.

Spinler, Stefan, Arnd Huchzermeier, and Paul R. Kleindorfer. 2002. An options approach to enhance economic efficiency in a dyadic supply chain. Cost management in supply chains, 349-360. Physica, Heidelberg.

Spinler, Stefan, Arnd Huchzermeier, and Paul R. Kleindorfer. 2003. Risk hedging via options contracts for physical delivery. OR Spectrum 25 (3): 379-395.

Tomlin, Brian. 2006. On the value of mitigation and contingency strategies for managing supply chain disruption risks. Management Science 52 (5): 639-657.

Trigeorgis, Lenos. 1993. The nature of option interactions and the valuation of investments with multiple real options. Journal of Financial and quantitative Analysis 28 (1): 1-20.

Trigeorgis, Lenos. 1996. Real options: Managerial flexibility and strategy in resource allocation. Cambridge: MIT Press.

Tsai, Wen-Hsien, and Chien-Wen Lai. 2007. Outsourcing or capacity expansions: Application of activitybased costing model on joint products decisions. Computers \& Operations Research 34 (12): 3666-3681.

U.S. Department of the Treasury. 2017. Daily Treasury Yiel Curve Rates. https://www.treasury.gov/ resource-center/data-chart-center/interest-rates/Pages/TextView.aspx?data=yield. Accessed 22 November 2017.

Ullrich, Christian. 2013. Valuation of IT investments using real options theory. Business \& Information Systems Engineering 5 (5): 331-341.

Vyatkin, Valeriy, Zoran Salcic, Partha Roop, and John Fitzgerald. 2007. Now That's Smart! IEEE Industrial Electronics Magazine 1 (4): 17-29.

Wang, Shiyong, Jiafu Wan, Di Li, and Chunhua Zhang. 2016. Implementing Smart Factory of Industrie 4.0: An outlook. International Journal of Distributed Sensor Networks, 12 (1): 3159805.

Wickramasinghe, G.L.D., and Asanka Perera. 2016. Effect of total productive maintenance practices on manufacturing performance: Investigation of textile and apparel manufacturing firms. Journal of Manufacturing Technology Management 27 (5): 713-729.

Wu, Dong. J., Paul R. Kleindorfer, and Jin E. Zhang. 2001. Integrating contracting and spot procurement with capacity options. INTACH 1996 CISDEM-Community Information Services on Development and Environment Matters.

Wu, Dong J., Paul R. Kleindorfer, and Jin E. Zhang. 2002. Optimal bidding and contracting strategies for capital-intensive goods. European Journal of Operational Research 137 (3): 657-676. 
Wu, Dazhong, Matthew J. Greer, David W. Rosen, and Dirk Schaefer. 2013. Cloud manufacturing: Drivers, current status, and future trends, Proceedings of the ASME 2013 international manufacturing science and engineering conference. MSEC 13, Madison, Wisconsin, USA.

Wu, Feng, H.Z. Li, Lap K. Chu, Domenic Sculli, and Kun Gao. 2009. An approach to the valuation and decision of ERP investment projects based on real options. Annals of Operations Research 168 (1): 181-203.

Xometry. 2017. One-Stop Shop for Manufacturing on Demand. https://www.xometry.com/. Accessed 23 November 2017.

$\mathrm{Xu}$, Xun. 2012. From cloud computing to cloud manufacturing. Robotics and Computer-Integrated Manufacturing 28 (1): 75-86.

Publisher's Note Springer Nature remains neutral with regard to jurisdictional claims in published maps and institutional affiliations. 